\title{
A SURPREENDENTE TRAJETÓRIA DE UM LIVRO REBELDE
}

Publicado na web em 23/01/2020

Substâncias Carboniladas e Derivados, Paulo Roberto Ribeiro Costa, Ronaldo Aloise Pilli, Sergio Pinheiro, $2^{a}$ Edição, EditSBQ, São Paulo - 2019, ISBN 978-85-64099-23-4, 464 páginas + xviii.

Escrever resenha de livro na era das redes sociais parece fora de moda, uma vez que a descrição técnica do livro pode não atrair tanto a atenção de potenciais leitores jovens. Mas acredito que resenhar pode ser útil por outro aspecto - o registro do que o livro não conta somado a algum detalhe que o fast-food digital dispensa. Escolher qual resenhar é, naturalmente, uma questão de afinidade, acrescida de se há algo a contar que o prefácio e a apresentação já não tenham esgotado. Para além desses fatos, o livro deve merecer este esforço por ser intelectualmente interessante a um público específico, desejável que amplo. Mas gosto mesmo é de livro diferente dos que abundam nas prateleiras com títulos e temas já visitados.

Existem livros que são rebeldes mesmo que escritos por autores clássicos. O livro brasileiro-universal "Substâncias Carboniladas e Derivados" (doravante denominado SC) é um desses. Se considera rebelde um qualitativo exagerado para um livro, sigamos a sua trajetória.

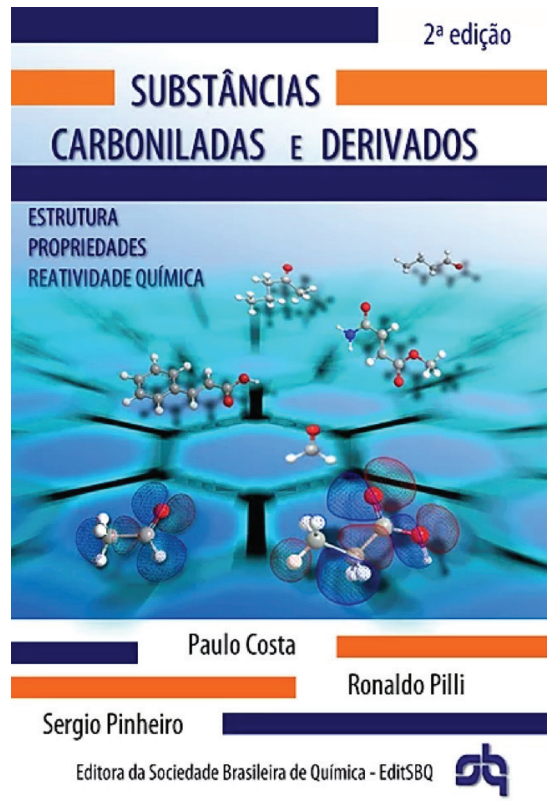

Capa da segunda edição de Substâncias Carboniladas

Comparada à primeira edição, que tinha como quarto autor o Professor Mário Luiz A. A. Vasconcellos e que não pode juntar-se aos demais autores na reescrita da segunda edição, $\mathbf{S C}$ cresceu quase $20 \%$ em número de páginas. O projeto gráfico é muito, mas muito bom, com o uso de cores que fazem as explicações gráficas deveras didáticas. As imprecisões dos esquemas da primeira edição, fruto da reescrita por não-químicos na etapa de editoração, foram praticamente eliminadas. Digo praticamente pois, na primeira leitura, não consegui localizar.

Os capítulos são ordenados com os títulos: 1 -Aldeídos, cetonas, iminas e nitrilas; 2 - Derivados de ácidos carboxílicos e ácido carbônico; 3 - Substâncias carboniladas $\alpha, \beta$-insaturadas e derivados. Em cada um deles há subtítulos que se mantêm mais ou menos inalterados em cada capítulo (Fontes e usos, Propriedades físicas, Estrutura, Reatividade química, Reações químicas). Dentro desses, mais divisões ainda com tópicos específicos, o que leva a situações de detalhamento como ocorre, por exemplo, no capítulo 3 que termina no item 3.5.4.4.2! Antes que pareça um exagero, informo que essas subdivisões proporcionam localizar, com facilidade, aspectos específicos que um leitor esteja procurando ou queira revisar, tornado o uso do livro muito prático.

O livro tem uma home page onde é possível obter várias informações, inclusive como proceder para compra do mesmo (https://www.livrosubstanciascarboniladas.com). Adicionalmente, SC dispõe de uma página no Facebook (https://www.facebook.com/ substanciascarboniladasederivados/) como estratégia de divulgação e aproximação com o leitor jovem (e outros nem tanto assim), mas estas informações não se encontram no livro, o que seria interessante numa futura reimpressão. Existem exercícios, porém o número é muito aquém do potencial do livro. Uma possível solução talvez venha ser a inserção de exercícios na home page.

A anatomia de $\mathbf{S C}$ merece ser comentada por se tratar de um livro denso em conteúdo e granulometria, fazendo com que sua leitura possa ser feita confortavelmente numa mesa, mantendo-se aberto na página desejada (tentei ler deitado, o peso do livro incomoda). Coisa chata é livro que precisamos impor força para que fique aberto. SC não, e ainda suas páginas acetinadas ressaltam a qualidade das figuras e textos destacados em boxe azul. Por sinal, estes boxes contêm informações sobre procedimentos de síntese que ilustram a aplicação de conceitos e teorias na vida real da química orgânica. Apresentam também pitadas de história da química orgânica, exercícios, aspectos bioquímicos e, até mesmo, aprofundam explicações.

Há pequenos reparos a fazer que numa reimpressão podem ser facilmente eliminados, mas não comprometem em nada a obra. Assim é que não encontrei a ficha catalográfica, apesar de encontrar as informações que se espera de uma nas páginas I e IV. Na capa há o subtítulo "Estrutura, propriedade, reatividade química" que desaparece no resto do livro, de forma que o título é mesmo "Substâncias Carboniladas e Derivados”. O Prólogo não está contido no Sumário, o que faz a primeira informação aparecer já na página 5 .

Os autores têm se empenhado na divulgação e consolidação do livro como peça importante na formação das novas gerações de profissionais da química e áreas afins, com concorridos cursos itinerantes apresentando o assunto tratado em SC, como os que ocorreram no Rio de Janeiro, Salvador e Belo Horizonte após o lançamento da atual edição na 41 ${ }^{\text {a }}$ Reunião Anual da Sociedade Brasileira de Química. Impressiona a empolgação dos autores nesta empreitada, como se fossem jovens docentes no início da carreira.

É preciso ponderar a quem se destina o texto de SC. Serve tanto a alunos de graduação quanto de pós-graduação. Todavia, para alunos de graduação julgo que o melhor aproveitamento é para os que tenham vencido os cursos básicos de química orgânica, mas não impede que o livro seja adotado como leitura complementar já nesse nível, com estudo de tópicos específicos orientados pelo professor (daí a relevância do detalhamento do tipo 3.5.4.4.2!). Serve muito bem para cursos do ciclo profissionalizante da graduação. Para todos os leitores, inclusive nós professores, sana eventuais lacunas de formação ao ampliar a maturidade do uso da Teoria de Ligação de 
Valência e da Teoria do Orbital Molecular em química orgânica. Há explicações de fenômenos químicos com essas duas teorias de forma contínua, simultânea e suave, um aspecto didático muito peculiar de SC. É uma clara evidência da tradição das duas principais Escolas de síntese orgânica que contribuíram na formação de gerações de professores para praticamente todo o Brasil, quando a formação de doutores na área era centrada quase que exclusivamente no Rio de Janeiro e em São Paulo.

A qualidade didática e a primazia da abordagem única fazem de "Substâncias Carboniladas e Derivados" leitura obrigatória para todo químico em formação e, para os que estão na pós-graduação, uma necessidade. Não consigo considerar entre nós, na atualidade, um químico orgânico que possa ser razoavelmente culto na área que não tenha lido SC. Os bordões "você precisa ler carboniladas" ou “você não leu carboniladas?” são formas singelas de sugerir a adesão ao livro. Pratico com sucesso. Fica a dica.

Estive nos lançamentos da primeira (2003) e da segunda (2019) edições de SC. Nos dois momentos estavam presentes os autores Paulo e Pilli. Também me lembro que Lethycia Tannuri e Paula Pilli, as respectivas esposas, estavam presentes e muito felizes. Conto estes fatos pois é comum encontrarmos agradecimentos a familiares devidamente apontados nos livros pois escrever um livro parece mesmo movimentar e/ou modificar a rotina de uma família, ainda mais quando os autores são Professores Universitários dessa dimensão e com agenda intensa de trabalho. Parece aqui que o projeto da segunda edição contaminou, no melhor sentido do termo, as famílias: Lethycia comanda a divulgação digital do livro e Beatriz Tannuri Costa, filha de Paulo e Lethycia, foi a responsável pelo projeto gráfico, editoração eletrônica, capa e contracapa da segunda edição.

Existem alguns aspectos pitorescos sobre a história desse livro que o leitor não encontrará nas páginas de SC. Quando a Sociedade Brasileira de Química - SBQ - decidiu publicar livros com a sua chancela iniciando o selo editorial EditSBQ, SC foi selecionado para ser o livro inaugural dessa nova fase da Sociedade. Tempos depois, tive a sorte de estar na reunião da Diretoria e Conselho da SBQ que tomou a decisão de retomar às atividades editoriais. Procurávamos um nome para ser o responsável da EditSBQ. Definido o perfil necessário, resgatei a história de sucesso da primeira edição de SC e sugeri o nome de Pilli, que era contemporâneo naquela gestão da Diretoria e Conselho da SBQ. Sabia que estava em curso uma nova edição de SC e defendi a proposta da nova publicação pela EditSBQ. Sendo professor de química orgânica e usuário da primeira edição, foi fácil desenrolar o rosário de bons argumentos, como a originalidade e o caráter didático do livro na abordagem do tema, sem paralelo em outro livro, mesmo em língua inglesa. Pilli se tornou o primeiro coordenador da EditSBQ na nova fase e a conduziu com sua profunda dedicação ao trabalho, que lhe é tão peculiar, o que resultou na quebra da dormência da SBQ na edição de livros na área de química.

Quando da preparação da primeira edição houve muito debate sobre o livro inaugural com o selo da SBQ. À época, Paulo e Pilli eram o diretor e o vice-diretor, respectivamente, da Divisão de Química Orgânica da SBQ (DQO), e resolveram apresentar o projeto do livro, já bem adiantado, na assembleia da DQO. Paulo não pode comparecer àquela Reunião Anual da SBQ, e Pilli então presidiu a assembleia. Quem o conhece sabe quão comedido Pilli é na hora de apresentar um projeto, no sentido de não fazer autoelogio. Estava lá e fiz alguns questionamentos e outros fizeram também vários. O rumo da assembleia mudou e houve um momento que foi questionada a pertinência de se publicar um livro com o selo da SBQ sobre um tema tão restrito. Somada às então "imperfeições" do livro inconcluso levantadas por alguns, parecia que a assembleia iria decidir pela extinção de SC. Solicitei a palavra e defendi a publicação dizendo que preferia um livro imperfeito a livro nenhum. Várias outras falas se avolumaram na defesa da publicação, inclusive lembrando que a decisão de publicar ou não, não era nossa, mas quem frequenta a assembleia anual da DQO sabe como funciona esse organismo vivo... Ao término, Pilli sentou-se ao meu lado e disse um discreto obrigado.

$\mathrm{Na}$ preparação da segunda edição tive a oportunidade de ver o capítulo 1 ainda na fase de reescrita e pude perceber que não se tratava de uma simples revisão de eventuais erros de formatação da primeira edição, pois o conteúdo do anexo da primeira edição foi diluído ao longo dos capítulos requerendo a reorganização do livro inteiro. Em outra oportunidade vi a proposta da nova capa. Lethycia me perguntou, num email ou whats zap, se eu havia gostado; disse que não, que não parecia com capa de livro brasileiro. A capa mudou.

SC é livro singular, não é uma imitação de livro estrangeiro e se estabeleceu pelo avesso: de tão original e brasileiro demanda ser explicado ao resto do mundo não falante da última flor do Lácio, coisa que a tradução para o inglês suprirá. Soube, pelos próprios autores, que uma tradução está em curso a ser publicada pela Royal Society of Chemistry, inclusive com elogioso parecer já exarado por consultor daquela casa editorial. Não conheço outro livro da área de química que teve esta trajetória. SC, esse livro rebelde, vai ganhar o mundo! Nós, por sorte nossa, o saboreamos na língua falada no berço.

Como avaliar a maturidade de um dado ramo da ciência? Muitos tem suas métricas científicas para esta pergunta. Me arrisco a considerar que escrever um livro único, de originalidade profunda, faz suspeitar da boa maturidade da química orgânica brasileira, e da síntese orgânica em especial (ramo dos autores), pois se fosse ciência incipiente não proporcionaria um livro deste alcance. E aqui fica o principal: a melhor contribuição à ciência e à formação das novas gerações de profissionais é a que é feita de forma original e nossa, tornando-se universal. É melhor que ficarmos caricaturando os outros. Fico feliz por ter em nossas mãos a nova edição de um livro tão nosso, tão de todos, tão brasileiro e universal. Obrigado Paulo, Pilli e Sérgio.

Como bom baiano fui consultar todos os santos e orixás, que vaticinaram: manda inscrever o tal livro para o Prêmio Jabuti de 2020...

Silvio Cunha ${ }^{\mathrm{a}, \mathrm{b}}$

anstituto de Química, Universidade Federal da Bahia, 40170-115 Salvador - BA, Brasil.

${ }^{b}$ INCT de Energia e Ambiente, Universidade Federal da Bahia, 40170-290 Salvador - BA, Brasil. 